\title{
EGFR modulates complement activation in head and neck squamous cell carcinoma
}

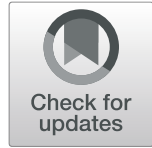

Anas H. A. Abu-Humaidan ${ }^{1,2^{*}}$ (D) Lars Ekblad ${ }^{3}$, Johan Wennerberg ${ }^{4}$ and Ole E. Sørensen ${ }^{1}$

\begin{abstract}
Background: The epidermal growth factor receptor (EGFR) is pivotal for growth of epithelial cells and is overexpressed in several epithelial cancers like head and neck squamous cell carcinoma (HNSCC). EGFR signalling is also involved in diverse innate immune functions in epithelia. We previously found a role for EGFR in modulating the complement system in skin, this prompted an investigation into EGFR role in complement modulation in HNSCC.

Methods: We used patient derived HNSCC cell lines with varying sensitivities to EGFR inhibitors, and generated EGFR inhibition resistant cell lines to study the role of EGFR in modulating complement in HNSCC.

Results: We found that HNSCC cell lines activate the complement system when incubated with human serum. This complement activation was increased in cell lines sensitive to EGFR inhibition following the use of the tyrosine kinase inhibitor Iressa. Sensitive cell line made resistant to EGFR-inhibitors displayed complement activation and a decrease in complement regulatory proteins even in the absence of EGFR-inhibitors. Complement activation did not cause lysis of HNSCC cells, and rather led to increased extracellular signal-regulated kinase (ERK) phosphorylation in one cell line.

Conclusion: These data indicate that EGFR has a complement modulatory role in HNSCC, and that a prolonged EGFR-inhibition treatment in sensitive cancer cells increases complement activation. This has implications in understanding the response to EGFR inhibitors, in which resistance and inflammatory skin lesions are two major causes for treatment cessation.
\end{abstract}

Keywords: EGFR, HNSCC, Complement activation, Complement regulation, Tyrosine kinase inhibitor, Iressa, Cancer microenvironment

\section{Background}

The complement system is a conserved cornerstone of innate immunity $[1,2]$. More than 30 proteins comprising the complement system play a role in various immune and homeostatic functions, from killing of pathogens and clearance of apoptotic cells [3-6], to recently discovered roles in angiogenesis and tissue regeneration [7-9]. Hence, activation of the complement system is tightly regulated both at the level of initiation and amplification [10-12]. An important part of this regulation occurs locally in tissue [13], indeed, almost all

\footnotetext{
* Correspondence: A.abuHumaidan@ju.edu.jo

'Division of Infection Medicine, Department of Clinical Sciences, Lund University, Lund, Sweden

${ }^{2}$ Division of Microbiology, Faculty of Medicine, The University of Jordan,

Amman, Jordan

Full list of author information is available at the end of the article
}

nucleated cells express at least one complement regulator on their surface [14]. This local regulation is highlighted by tissue specific manifestations of systemic complement deficiencies [12, 15, 16].

The role of the complement system in cancer development is unclear [17], but data show complement activation in the microenvironment of several epithelial cancers [18-20], and elevated levels of activation fragments in serum of cancer patients [18, 20, 21]. Complement activation has been traditionally seen as an immune surveillance mechanism against cancer development [22]. Consequently, antibody therapies aim to promote complement dependent cytotoxicity [23], but malignant cells tend to upregulate the expression of complement regulatory proteins [24], highlighting a

(c) The Author(s). 2020 Open Access This article is distributed under the terms of the Creative Commons Attribution 4.0 International License (http://creativecommons.org/licenses/by/4.0/), which permits unrestricted use, distribution, and 
selective pressure exerted on these cells to minimize the harmful effects of complement.

On the other hand, several studies demonstrate a cancer promoting effect of complement activation fragments, either through recruitment of immunomodulatory cells like myeloid-derived suppressor cells [25], or by directly interacting with receptors (e.g. C3aR, C5aR) that activate growth signalling pathways like ERK1/2, or EGFR transactivation [26, 27]. In many carcinomas, local complement expression and activation promote cancer growth [28]. The finding that $\mathrm{C} 5 \mathrm{aR}$ inhibition retarded cancer growth in mice to a similar extent exhibited by anticancer drugs [25] warrants more detailed studies of complement regulatory mechanisms in the cancer microenvironment.

EGFR inhibition therapy is frequently used in treatment of HNSCC [29], and inhibition of EGFR signalling in epithelial tissues induces a local inflammatory environment [30]. An inflammatory environment is integral for the neoplastic process in general [31], and even more so in HNSCC [32-34]. Interestingly, although inflammation is beneficial for growth of HNSCC, EGFR inhibition-induced inflammatory skin lesions during treatment is the best predictor for treatment response. We previously found that EGFR regulated complement expression in primary keratinocytes, and consequently, we now sought to examine if EGFR has a role in regulation of complement activation in HNSCC.

In this study we found that EGFR inhibition treatment induced complement activation on the cell surface of cancer cells. Complement activation did not cause cell lysis but rather increased ERK phosphorylation for one of the cell lines tested.

\section{Materials and methods Reagents}

Iressa was purchased from Sigma-Aldrich; cetuximab (Erbitux) from Merck. Affinity purified polyclonal rabbit antibodies against the C3d domain of human C3, and against the C4c domain of human C4 were from Dako. Monoclonal mouse anti C5b-9 antibody, human purified C1q, C1q-depleted serum, and factor B-depleted serum were from Quidel. Monoclonal mouse antibody against GAPDH, affinity purified rabbit antibodies against ERK and phosphorylated ERK were from R\&D systems.

\section{Cell culture}

Head and neck squamous cell carcinoma cell lines LUHNSCC- $[4,5,7,8]$ - referred to hereafter as $H N[4,5,7$, 8] in the figures - were generated at the Divisions of Ear, nose and throat/ Head and neck Surgery and Oncology at Lund University as previously described [35, 36]. A431 (Human squamous carcinoma, ECACC no. 85090402) and A549 (Human Caucasian lung carcinoma, ECACC no. 86012804) were from Sigma. All cell lines were cultured in DMEM supplemented with $10 \%$ heat inactivated foetal bovine serum (FBS) and antibiotics $(30 \mu \mathrm{g} / \mathrm{mL}$ Gentamicin, $15 \mathrm{ng} / \mathrm{mL}$ Amphotericin, Gibco). HN4 from the floor of the mouth, HN5 from the gingiva, HN7 from a recurrence of a squamous cell carcinoma of the bucca, and HN8 from the bucca. Primary keratinocytes were obtained from Lonza and grown in serum-free medium (KGM Gold Bullet Kit) from Lonza. For 2-4 d after seeding, the keratinocytes received $100 \mathrm{ng} / \mathrm{ml}$ EGF. For all cell types, medium was changed to KGM Gold medium without insulin or EGF for $24 \mathrm{~h}$ before complement activation.

\section{Cetuximab resistant sublines}

Cell lines HN4 and HN5 were treated with increasing cetuximab concentrations doubled every 2 weeks. Dose increase was performed by splitting the cells at the lower concentration, and after 3 days the medium was changed to medium with double cetuximab concentration. The cell lines not treated with cetuximab were grown and split in the same manner as the cetuximab-treated cells. When maximum concentration for each cell line (2560 $\mathrm{nmol} / \mathrm{L}, 0.39 \mathrm{mg} / \mathrm{mL}$ ) was reached, the cells were grown for 2 months at that concentration before freezing. Growth was measured using the Sulforhodamine B colorimetric assay as described below.

Before complement experiments, these cells were passaged at least three times with several medium changes in each passage, in medium without cetuximab to avoid possible complement activation due to cetuximab.

\section{Iressa sensitivity assay}

To measure Iressa-mediated growth inhibition of cell lines HN4, HN5, HN7 and HN8, cells were seeded at densities averaging $2.5^{*} 10^{5}$ cells/ well, in 12-well plates in DMEM supplemented with $10 \%$ heat inactivated FBS and antibiotics. The next day, medium was changed to KGM bullet kit without EGF or insulin, with or without $5 \mu \mathrm{mol} / \mathrm{L}$ or $10 \mu \mathrm{mol} / \mathrm{L}$ Iressa. Cell counts were done at $24 \mathrm{~h}$ and $48 \mathrm{~h}$ after Iressa treatment using 0.4\% Trypan blue staining in LUNA ${ }^{\mathrm{m}}$ Automated Cell Counter (Logo Biosystems).

\section{EGFR activation and inhibition}

The day cells were confluent, medium was changed to KGM bullet kit without EGF or insulin (Lonza). The day after confluency, cells were treated with $10 \mu \mathrm{mol} / \mathrm{L}$ Iressa for $48 \mathrm{~h}$ in new KGM without EGF or insulin. Nontreated control cells were grown in the same medium but without treatment.

\section{Real-time polymerase chain reaction ( $R-T$ PCR)}

cDNA was synthesized from 600 ng purified RNA using iScript cDNA synthesis kit (Bio-Rad), according to the instructions given by the manufacturer. RNA expression 
of complement components was analysed with quantitative R-T PCR using iQ SYBR Green Supermix (Bio-Rad). Amplification was performed at $55^{\circ} \mathrm{C}$ for 40 cycles in iCycler Thermal Cycler (Bio-Rad), and data were analyzed using iCycler iQ Optical System Software. RNA expression was normalized using GADPH as housekeeping gene.

\section{Complement activation}

KGM medium without EGF or Insulin was added to the cells together with $10 \%$ normal human serum (NHS) or $10 \%$ heat-inactivated human serum (HIS). After 3-h incubation at $37^{\circ} \mathrm{C}$, the cells were washed with PBS and fixed with $4 \%$ formaldehyde for $1 \mathrm{~h}(15 \mathrm{~min}$ on ice, 45 min at room temperature). After three washes in TBS $(10 \mathrm{mmol} / \mathrm{L}$ Tris, $500 \mathrm{mmol} / \mathrm{L} \mathrm{NaCl}[\mathrm{pH} 7.2])$, the cells were blocked with $5 \%$ goat serum $/ 5 \mathrm{mg} / \mathrm{mL}$ bovine serum albumin (BSA) at room temperature for $45 \mathrm{~min}$ in TBS. After blocking, inserts were washed once in TBS with $0,05 \%$ tween (TTBS). Primary antibodies were incubated in TTBS with $2.5 \%$ goat serum $/ 5 \mathrm{mg} / \mathrm{mL}$ BSA overnight in at $4{ }^{\circ} \mathrm{C}$ under rotation. Slides were washed three times in TTBS and incubated with secondary Abs for $2-4 \mathrm{~h}$ at room temperature. After washing the inserts were mounted on slides using Prolong Gold antifade reagent mounting medium with DAPI (Invitrogen).

\section{Immunofluorescence microscopy}

For fluorescence microscopy analysis, samples were visualized using a Nikon Eclipse TE300 (Nikon) inverted fluorescence microscope equipped with a Hamamatsu C4742-95 cooled charge-coupled device camera (Hamamatsu) and a Plan Apochromat objective (Olympus). C3, $\mathrm{C} 4$ and terminal complement complex (TCC) fluorescence around several fields was quantified using ImageJ, one representative experiment is shown.

\section{${ }^{125}$ I-labeled C1q binding assay}

HN4 and HN5 cells were treated with Iressa $(10 \mu \mathrm{mol} / \mathrm{L})$ for $48 \mathrm{~h}$. Subsequently, cells were incubated with $1 \mu \mathrm{g} /$ $\mathrm{mL}^{125}$ I-labeled C1q $(10,000 \mathrm{cpm})$ in $3.5 \mathrm{mg} / \mathrm{ml}$ bovine serum albumin for $30 \mathrm{~min}$ at $37^{\circ} \mathrm{C}$. Cells were washed three times in PBS and trypsinated. The radioactivity associated with the trypsinated cells was determined in a gamma counter (PerkinElmer).

\section{Sulforhodamine B (SRB) assay}

The colorimetric SRB assay was used to assess cell density, based on the measurement of cellular protein content [37]. Cells were washed and fixed by adding icecold $17 \%(\mathrm{w} / \mathrm{v})$ trichloroacetic acid (TCA) to each well and incubated for $1 \mathrm{~h}$ at $4{ }^{\circ} \mathrm{C}$, supernatant was discarded and plates rinsed five times with water and air-dried. Fixed cells were then stained in SRB solution $(0.4 \% \mathrm{w} / \mathrm{v}$
SRB in $1 \%$ acetic acid) for $20 \mathrm{~min}$ at room temperature, rinsed five times with $1 \%$ acetic acid to remove unbound SRB and air-dried. The dye was dissolved in $150 \mu \mathrm{L} 10$ $\mathrm{mmol} / \mathrm{L}$ Tris base and the absorbance measured at 565 nm.

\section{Growth assay}

HN5 cells were grown to around 20\% confluence. EGFR inhibition and subsequent complement activation were performed as described above. Briefly, cells were treated for $48 \mathrm{~h}$ with $10 \mu \mathrm{mol} / \mathrm{L}$ Iressa, and subsequently incubated for $3 \mathrm{~h}$ in $10 \%$ NHS, $10 \%$ HIS or medium only. Afterwards, growth was measured using an SRB assay either directly ( $3 \mathrm{~h}$ time point) or after $21 \mathrm{~h}(24 \mathrm{~h}$ time point) of complement activation.

\section{Scratch assay}

To see if complement activation promotes migration of cells, we used a modified scratch assay. The day prior to confluence of HN5 cells, medium was changed to KGM bullet kit without insulin or EGF and with $10 \mu \mathrm{mol} / \mathrm{L}$ Iressa. This medium was used during the remainder of the experiment. The day after confluence, a scratch was made with a $200 \mu \mathrm{L}$ pipette tip. Immediately after the scratch, $10 \%$ NHS or HIS was added for $3 \mathrm{~h}$, and pictures were taken. Medium was changed back to medium with Iressa (to minimize the effect of cell growth on the assay) and pictures were taken at $24 \mathrm{~h}$ from serum addition. Open areas not containing cells after the scratch were analyzed using the software TScratch [38]. Area of the scratch at $24 \mathrm{~h}$ was presented as a percent of the original scratch area, using the following formula: (Open area at $24 h /$ Open area at $0 h) * 100 \%$, where values below $100 \%$ represent closure of the original scratch.

\section{SDS-PAGE and immunoblotting}

SDS-PAGE and immunoblotting were performed according to the instructions from the manufacturer (BioRad). After transfer of proteins from the polyacrylamide gels, the polyvinylidene difluoride (PVDF) membrane was fixed for $30 \mathrm{~min}$ in TBS with $0.05 \%$ glutaraldehyde (Sigma-Aldrich) and blocked with 5\% BSA. For visualization of the proteins, the PVDF membranes were incubated overnight with primary antibody. The following day, the membranes were incubated for $2 \mathrm{~h}$ with horse radish peroxidase (HRP) conjugated secondary antibody and visualized by SuperSignal West Pico Chemiluminescent Substrate (Pierce), Quantification of signal was done using Image lab. The PVDF membrane was stripped for $20 \mathrm{~min}$ in $0.2 \mathrm{~mol} / \mathrm{L}$ glycine $(\mathrm{pH} 2.5)$ and $1 \%$ SDS, washed twice with TBS with $0.05 \%$ Tween 20 (TTBS), and finally blocked before incubating overnight with a new antibody. 


\section{ERK activation}

ERK activation was monitored by quantifying the signal of Western blots, phosphorylated ERK signal was measured using chemiluminescence of and normalized to total ERK.

\section{Statistical analysis}

Values were log-transformed, and Student's t-test was performed on log transformed values to compare different treatments. " denotes $p<0.05$, ${ }^{* *}$ denotes $p<0.01$.

\section{Results}

Head and neck squamous cell carcinoma (HNSCC) activate the complement system when incubated with human serum

To investigate the role of the complement system in HNSCC, we first tested complement activation reflected by deposition of complement components $\mathrm{C} 3$ and TCC in 4 patient-derived HNSCC cell lines, and compared the activation to primary human epidermal keratinocytes from adult donors. Using immunofluorescence microscopy, we found that incubation with NHS as a source of complement but not HIS lacking complement activity, led to a significant increase in TCC deposition in HNSCC cells in comparison to primary keratinocytes (Fig. 1a). Interestingly, pooled quantification of $\mathrm{C} 3$ and TCC deposition, obtained by subtracting the fluorescence signal of cells treated with NHS from those treated with HIS, showed no significant difference between HNSCC and primary keratinocytes in C3 deposition, but only in TCC staining (Fig. 1b).

The significant increase in TCC staining in HNSCC cells prompted us to investigate the expression of complement regulatory proteins (CRP) CD46, CD55, CD59 and Factor $\mathrm{H}$ which are important in regulating complement activation at the cell surface. Using R-T PCR, no significant difference was seen in CD46 and CD55 expression, but CD59 expression - mainly responsible for inhibition of TCC formation [39]- was significantly lower in HNSCC when compared to primary keratinocytes, A431 and A549 (Fig. 1c). Factor H was expressed more in HNSCC cell lines in comparison to primary keratinocytes which had barely detectable levels of Factor $\mathrm{H}$ (Fig. 1c). This suggested that the decrease in CD59 expression could be the reason for the observed increased deposition of TCC in HNSCC.

While complement activation was heterogeneously found across the monolayer (Fig. 1a), we noticed that cells with dysmorphic nuclei did not show a similar pattern of complement activation (sup. Fig. 1). So we investigated apoptosis and necrosis in the cell monolayers using Annexin $\mathrm{V}$ which binds to phosphatidylserine, a marker of apoptosis when it is on the outer leaflet of the plasma membrane, and Ethidium homodimer III (EtD-
III) which is a highly positively charged nucleic acid probe, impermeant to live or apoptotic cells, but stains necrotic cells. We found very few positive cells for apoptosis or necrosis (less than 5\%) (Fig. 1d), this is comparable to what we noticed before in primary keratinocytes incubated with NHS [40], such cells had condensed nuclei as shown by DAPI staining (Fig. 1d, arrow) and are similar in nuclear morphology to cells with a different complement deposition pattern (Sup Fig. 1).

To further validate that the observed complement activation was not related to apoptosis, we performed a double stain with Annexin V and TCC, and while most cells were negative for Annexin $\mathrm{V}$ staining, we found faint annexin $\mathrm{V}$ staining in cells with normal nuclear morphology (Fig. 1e) in HNSCC cell line (HN8), but cells stained with Annexin V showed less TCC staining, and the staining did not colocalize with TCC as C3 often does (Fig. 1a), further emphasizing that complement activation is not associated with phosphatidylserine or apoptotic cells.

In aggregate these data indicate that viable HNSCC cells activate the complement system to a greater extent than healthy epithelial cells as seen by the increase in TCC staining that was paralleled by a decrease in CD59 expression.

\section{EGFR inhibition and complement activation}

To examine if EGFR is involved in regulation of complement activation, we first confirmed the expression of EGFR using R-T PCR and found no significant differences in normalized EGFR expression between the 4 HNSCC cell lines (sup Fig. 2a). As we wanted to study the role of EGFR in regulation of complement activation, we inhibited EGFR using the tyrosine kinase inhibitor Iressa, an FDA approved EGFR inhibitor, rather than using the monoclonal anti-EGFR antibody Cetuximab, which is reported to activate complement through antigen-antibody complexes [41]. The HNSCC response to Iressa was first tested at different concentrations and time points (sup Figure $2 \mathrm{~b}$ ). The average growth inhibition following $10 \mu \mathrm{M}$ Iressa treatment for two of the cell lines HN4 and HN7 was 20 and 24\% respectively, while cell lines HN5 and HN8 averaged growth inhibition was 39 and 46\% respectively. This indicated that cell lines HN5 and HN8 were more sensitive to EGFR inhibition treatment, in accordance with a previous account that tested the sensitivity of those cell lines to Cetuximab [42]. Cell counts and viability following Iressa treatment were measured concurrently using an automated cell counter and trypan blue staining, it is important to note here that growth inhibition did not affect viability, which averaged above $90 \%$ in those cell lines at $10 \mu \mathrm{M}$ Iressa concentration (the highest concentration used). 


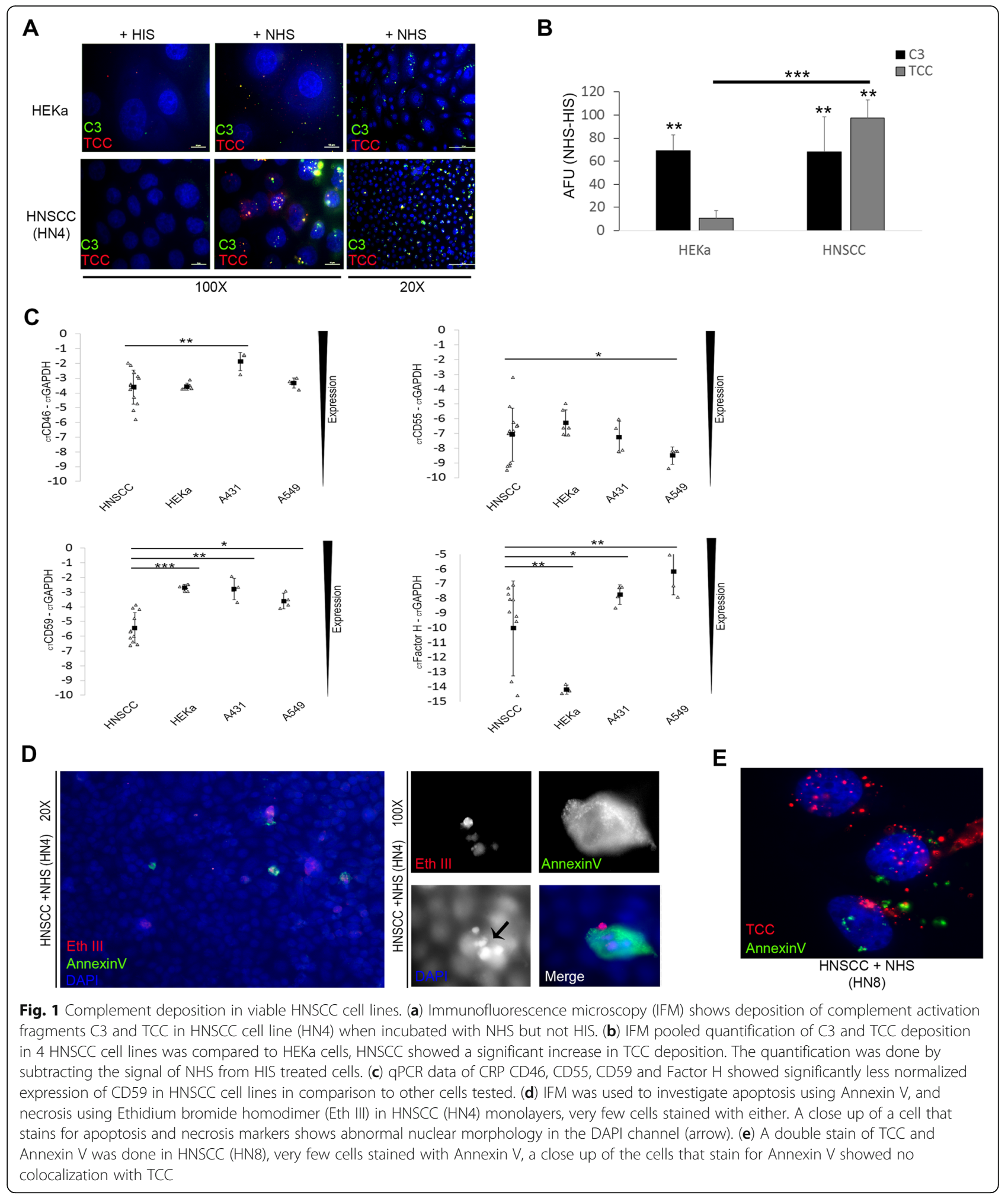

After confirming the response to EGFR inhibition, HNSCC cells were treated with Iressa for $48 \mathrm{~h}$. In general, we found an increase in TCC deposition in cell lines more sensitive to Iressa HN5 and HN8, the increased deposition of TCC was found after incubation with NHS but not HIS (Fig. 2a,c). In cell lines HN4 and HN7 displaying less growth inhibition, Iressa treatment did not increase TCC deposition after incubation with NHS (Fig. 2b,c). We also 


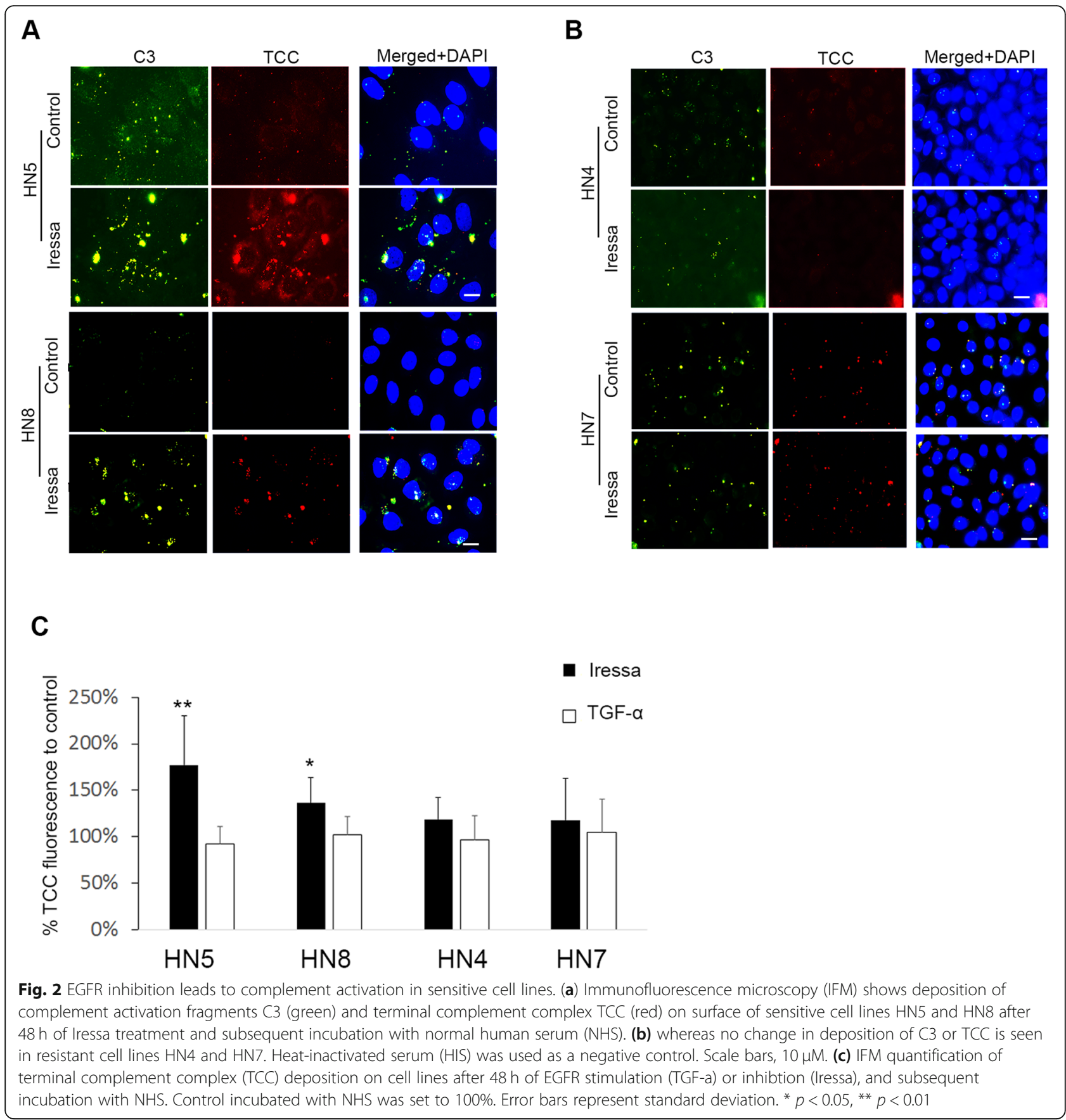

investigated if increased EGFR signalling using the potent EGFR ligand TGF- $\alpha$ could affect complement activation but found no significant difference in TCC deposition following transforming growth factor alpha (TGF- $\alpha$ ) treatment (Fig. 2c).

To further examine the complement activation mediated by EGFR inhibition on cancer cells, we focused on cell line HN5 with prominent complement activation after EGFR inhibition. Incubation of NHS with Iressatreated cancer cells led to increased deposition of $\mathrm{C} 4$
(Fig. 3a). This indicated activation of the complement system by the classical pathway or lectin pathway. Incubation of Iressa-treated cancer cells with $\mathrm{C} 1 \mathrm{q}$ depleted serum, or C1q only, did not lead to complement activation. However, complement activation was found after reconstitution of the C1q-depleted serum with $\mathrm{C} 1 \mathrm{q}$ (Fig. 3b). In contrast, incubation with Factor B depleted serum, which lacks an important component in the alternative pathway, led to complement deposition on Iressa-treated HN5 cells (Fig. 3b). This demonstrated 


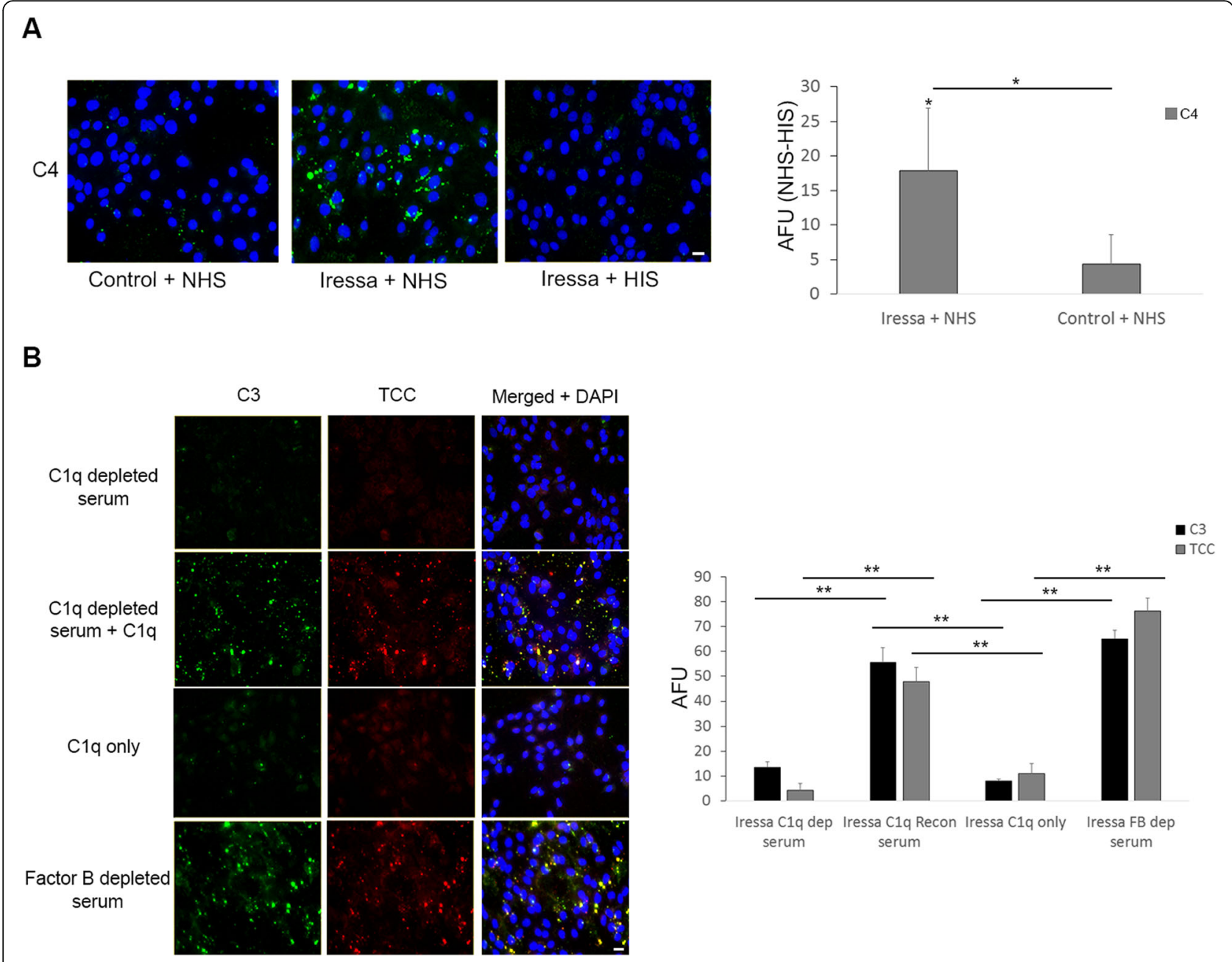

Fig. 3 Complement activation after EGFR inhibition is C1q dependent. (a) Immunofluorescence microscopy of HN5 cells shows deposition of C4 (green) on surface of Iressa treated cells after incubation with NHS, but not HIS. Controls are not treated with Iressa but incubated with NHS, C4 fluorescence was quantified in the bar chart to the right (b) Immunofluorescence microscopy of HN5 cells show no deposition of complement activation fragments C3 (green) and terminal complement complex TCC (red) on surface of HN5 cells after $48 \mathrm{~h}$ of Iressa treatment and subsequent incubation in C1q depleted serum, or C1q only $(100 \mu \mathrm{g} / \mathrm{mL})$, but when C1 depleted serum was reconstituted with C1q (100 $\mu \mathrm{g} / \mathrm{mL})$, complement activation was restored. While incubation with Factor B depleted serum, lacking ability to form alternative pathway C3 convertase, still shows complement activation, C3 and TCC fluorescence was quantified in the bar chart to the right. Scale bars, $10 \mu \mathrm{M}$. Experiment was repeated three times

that EGFR-inhibition by Iressa treatment led to C1qdependent complement activation.

Incubation of HN5 cells with radioactive labeled C1q, showed no increased binding of $\mathrm{Clq}$ in cells subjected to EGFR inhibition compared to controls, demonstrating that the observed complement activation was not due to increased C1q binding (Sup. Figure 3).

\section{Complement activation in sensitive cell lines made resistant to EGFR inhibition following prolonged cetuximab treatment}

The therapeutic effect of EGFR inhibition in cancers like HNSCC is mostly short-lived. Consequently, the cell lines were made resistant to EGFR inhibition with prolonged treatment with the EGFR neutralizing antibody cetuximab. The cells subjected to prolonged cetuximab treatment were passaged at least three times in medium without cetuximab to avoid cetuximab induced complement activation. After prolonged cetuximab treatment, the cell line HN5 previously sensitive to EGFR inhibition, did no longer display growth retardation following EGFR inhibition by neither cetuximab (Fig. 4a), nor Iressa (sup Fig. 2b). Interestingly, the HN5 cells made resistant to EGFR inhibition by prolonged cetuximab treatment (termed HN5cet), now displayed a higher ability to activate complement than the original cell line (Fig. 4b). Moreover, expression of CRP CD46, CD55 and CD59 was significantly reduced in the resistant subline HN5-cet, compared to the original 


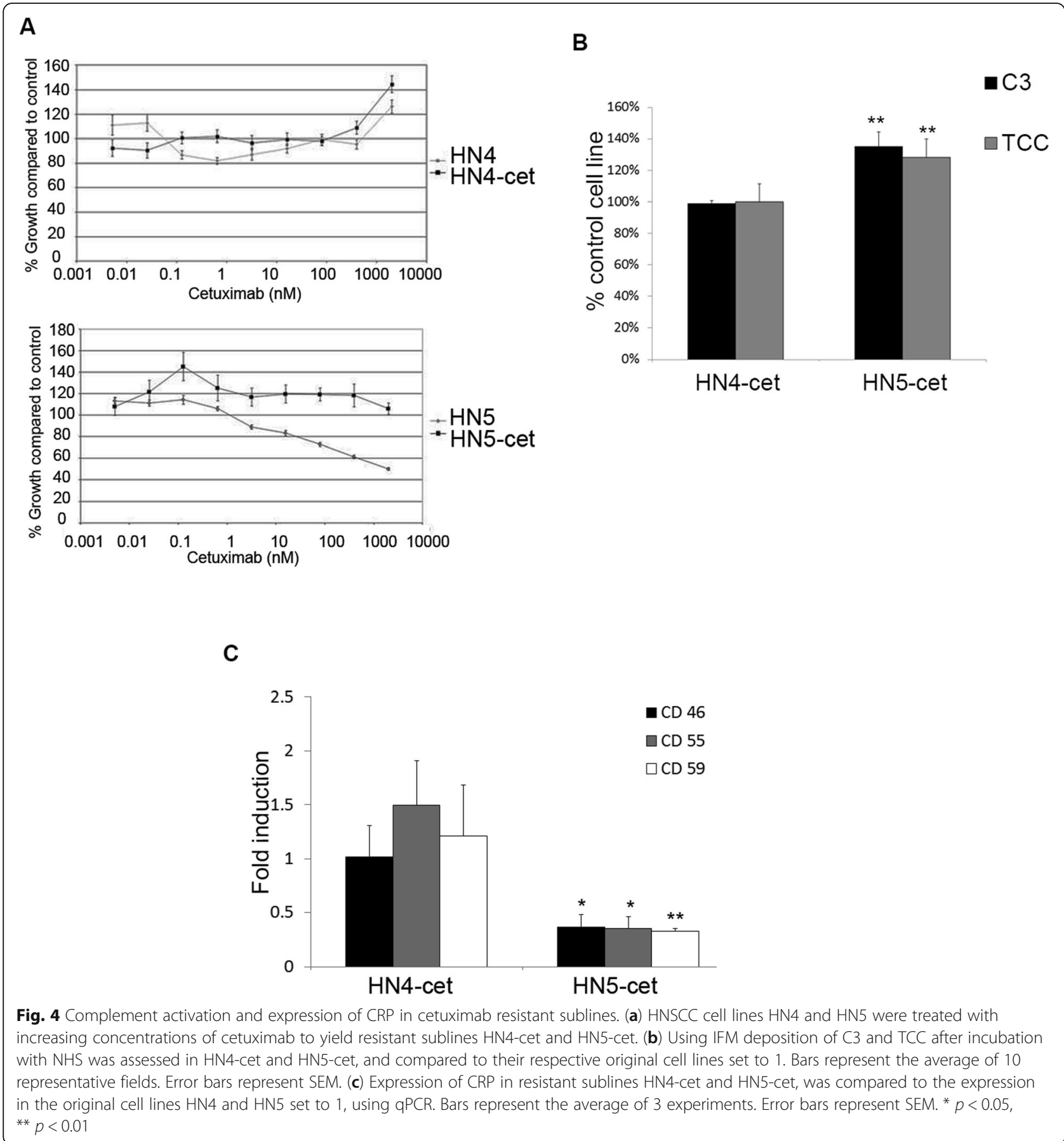

cell line HN5 (Fig. 4c). This demonstrated that prolonged EGFR-inhibition could promote complement activation independent of growth inhibition.

The cell line HN4, previously resistant to EGFRinhibition, was subjected to similar prolonged cetuximab treatment. In HN4-cet, no increase in the ability to activate complement was found, and the prolonged treatment with cetuximab did not decrease the expression of CRP (Fig. 4a-c).

\section{Complement activation and ERK phosphorylation}

Complement activation fragments have been shown to drive several pro survival signals such as ERK phosphorylation [26], important in cell proliferation and migration [43]. Using cell lysates after complement activation, we found an increase in phosphorylation of ERK1/2 after incubation of cells with NHS compared to HIS in cell line HN5, which had the most prominent complement activation after EGFR inhibition by 
Iressa, but not in other cell lines (Fig. 5d). To further illustrate the complement role in ERK phosphorylation, we incubated the HN5 cells with $\mathrm{C} 1 \mathrm{q}$ depleted serum, or $\mathrm{Clq}$ depleted serum reconstituted with C1q. Addition of $\mathrm{C} 1 \mathrm{q}$ to $\mathrm{Clq}$ depleted serum increased ERK1/2 phosphorylation demonstrating that Iressa-mediated complement activation increased ERK activation in the HN5 cell line (Fig. 5e). This indicates that complement activation observed can be beneficial for the cancer since it promoted ERK phosphorylation, which in addition to its role in cell proliferation, can promote resistance to complement lysis [44].

\section{Complement activation did not affect growth or migration}

Furthermore, we investigated the effect of complement activation on cell growth, cell migration, and growth factor expression in HN5 cells. Using the SRB assay cellular growth was measured 3 and $24 \mathrm{~h}$ after addition NHS or HIS to cells at $20 \%$ confluency. These cells displayed complement activation after incubation with NHS (data not shown). No significant difference in growth between cells treated with NHS or HIS was observed, indicating complement activation did not affect growth significantly (Fig. 5a).

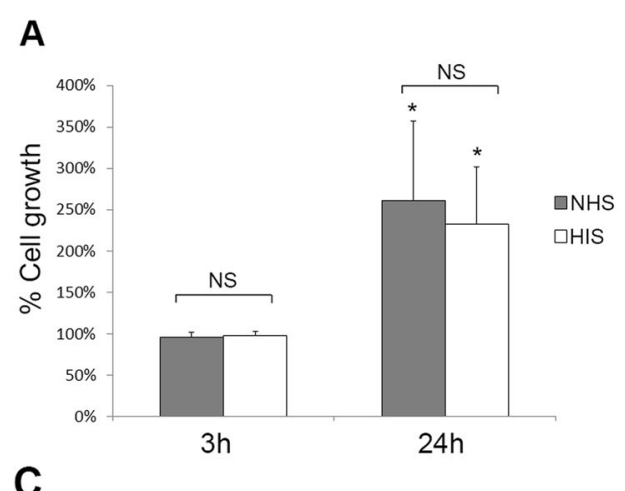

C

B
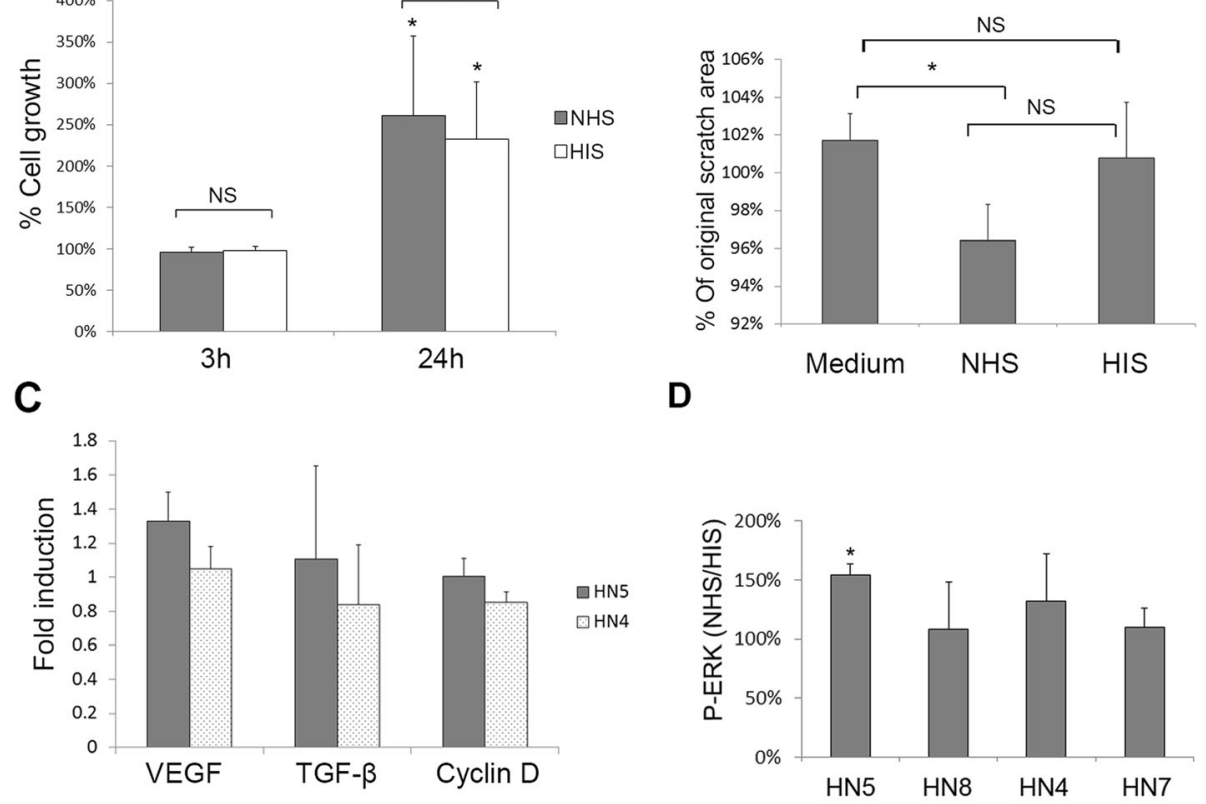

E

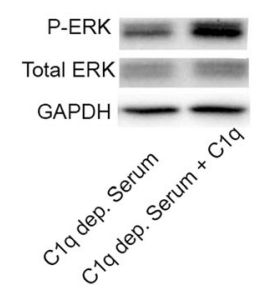

Fig. 5 Growth, migration and ERK-activation after complement activation. (a) Growth of sub-confluent HN5 cells was measured at 3 and 24 h after adding NHS or HIS, using an SRB assay. Growth of control cells treated with medium only is set to $100 \%$. No significant difference is found between HIS and NHS treatment, indicating complement activation did not affect growth. (b) A scratch was made in a monolayer of HN5 cells, and migration of cells into the open area was measured $24 \mathrm{~h}$ after adding NHS, HIS or medium only. The area of the original scratch at $0 \mathrm{~h}$ is set to $100 \%$. (c) Using QPCR, induction of growth and immune related genes was tested after $48 \mathrm{~h}$ of Iressa treatment and a subsequent $3 \mathrm{~h}$ complement activation using NHS. In cell lines HN5 and HN4, no significant difference in induction is seen when compared to HIS set to 1. (d) HNSCC cell lines were treated with Iressa for $48 \mathrm{~h}$ and subsequently incubated with 10\% NHS or HIS, cell lysates were then blotted for phosphorylated ERK (P-ERK) and normalized to total ERK (T-ERK). Bars represent the ratio of ERK phosphorylation after incubation with NHS compared to HIS, average of 3 experiments is used. (e) ERK phosphorylation was further tested in HN5 cells after incubation with C1q depleted serum, and C1q depleted serum reconstituted with C1q (100 $\mu \mathrm{g} / \mathrm{mL})$,and was shown with a representative blot. Error bars represent SEM, ${ }^{*} p<0.05$ 
We also investigated if the observed complement activation affected cell migration, using a scratch assay we measured cell migration in the presence of the growth inhibitor Iressa, to minimize the effect of cell growth on the assay. Though there was a difference between migration of cells after NHS compared to HIS treatment, this was not statistically significant (Fig. 5b). Finally, we examined the expression of growth-related genes possibly induced by complement activation in HN5, using the cell line HN4 as a control. We found no significant difference in gene induction between the two cell lines and hence no significant induction by complement activation (Fig. 5c).

\section{Discussion}

The aberrant growth of epithelial cancers commonly involves EGFR overexpression and activation. Consequently, EGFR inhibition with monoclonal antibodies or tyrosine kinase inhibitors is an FDA approved cancer therapy [45]. Apart from growth, EGFR regulates immune processes like production of chemokines and antimicrobial peptides [46], complement component expression and activation in the epidermis [47], and maintenance of skin homeostasis [48]. Accordingly, many patients undergoing EGFR inhibition therapy develop cutaneous toxicities, which serve as the best prognostic marker for treatment response [45]. The relationship between EGFR signalling and modulation of the immune response prompted us to investigate how EGFR inhibition therapy could affect an important player in the immune response to cancer, the complement system.

We found that viable HNSCC cells activated complement when incubated with NHS. The activation led to increased deposition of TCC when compared to primary keratinocytes. The increased TCC deposition could be explained by our finding of lower CD59 expression in HNSCC when compared to primary keratinocytes. Other reports confirm the presence of elevated systemic complement activation fragments in patients with HNSCC [21], as well as local complement activation [49]. Our finding is in contrast to previous reports indicating elevated CD59 in HNSCCs when compared to non-neoplastic epithelium using immunohistochemistry [50]. This difference could be to the heterogeneity of HNSCC types [51] or the fact that we looked at the relative mRNA levels and not at the protein level.

The only prior studies looking at EGFR and complement activation were investigating the complement fixing potential of monoclonal antibodies like Cetuximab, and the consequent complement dependent cytotoxicity $[23,52]$. In this study, we performed complement activation assays with the tyrosine kinase inhibitor Iressa, using HNSCC cell lines with varying growth sensitivities to EGFR inhibition with Iressa. To the best of our knowledge, this has not been previously investigated. We found deposition of complement components C3, $\mathrm{C} 4$ and TCC in these cell lines in a manner correlating with the growth inhibitory effect induced by EGFR inhibition. Indeed, cell lines that were more sensitive to EGFR inhibition showed a higher degree of complement activation following Iressa treatment than the more resistant cell lines. This activation was $\mathrm{C} 1 \mathrm{q}$ dependent, since C1q-depleted serum did not lead to deposition of complement components, but reconstitution of the depleted serum with $\mathrm{C} 1 \mathrm{q}$ did. This could give an extra level of control over complement activation since $\mathrm{C} 1 \mathrm{q}$ can be synthesized locally by immune cells found in HNSCC.

Since resistance following prolonged EGFR inhibition treatment commonly takes place in HNSCC, we generated cell lines that were resistant to EGFR inhibition treatment through continuous culture with increasing cetuximab concentrations. We found that the resistant subline significantly decreased CRP expression when compared to the original sensitive cell line. Moreover, incubation of the resistant subline with serum, demonstrated increased $\mathrm{C} 3$ and TCC deposition in comparison to the original sensitive cell line, indicating complement activation in the absence of growth retardation by an EGFR inhibitor.

Since inflammation in the tumour microenvironment is commonly modulated to benefit the tumour [31], and the observed complement activation was not due to apoptosis of EGFR inhibited cells, we hypothesize that cancer cells may modulate complement activation during growth inhibitory conditions. Although consequences of complement activation are complex and include interactions with several cell types and immune mechanisms [7], we found direct effects of this complement activation on the state of ERK1/2 phosphorylation, which drives mitogenic events in malignant cells and is reported to play a role in resistance to complement induced lysis [43]. However, we found no statistically significant effect of complement activation on cell growth, cell migration and growth factor expression by comparing cell incubated with NHS and HIS. This may be due to the presence of multiple growth factors in serum.

Inflammation is the best prognostic marker that a tumour is responding to EGFR inhibition therapy. However, the effects of EGFR inhibition on tumours is often short lived [45]. In this context, it is interesting to note that tumour cells that responded to EGFR-inhibition by growth retardation, promoted complement activation that led to ERK-activation. Furthermore, when sensitive cell lines became resistant to EGFR-inhibition, complement activation was present at the cell surface even after termination of EGFR inhibition. It is thus tempting to hypothesize that EGFR-mediated complement activation may, in certain situations, may promote tumour growth. 
Activation and regulation of the complement system need to be further investigated in cancers, especially in light of recent evidence that complement inhibitors can be used alongside cancer therapy to improve outcome $[53,54]$. Future in vivo experiments using tumour xenografts with varying sensitivities to EGFR inhibition, will hopefully elucidate the local complement response to EGFR inhibitors in the tumour microenvironment.

\section{Conclusions}

Our data demonstrate a complement modulatory role for EGFR in HNSCC. HNSCC cell lines activated complement when incubated with NHS, this activation was increased following EGFR inhibition in cell lines sensitive to Iressa. Complement activation was C1qdependent, was accompanied by a decrease in CRP, and led to increase ERK phosphorylation in one cell line. In cell lines resistant to Iressa, no increase in complement activation or decrease in CRP was found following EGFR inhibition. Prolonged EGFR-inhibition treatment in cancer cells sensitive to EGFR inhibition led to increased complement activation. This has implications in understanding the response to EGFR inhibitors in cancer treatment where resistance and inflammatory skin lesions are two major causes for treatment cessation.

\section{Supplementary information}

Supplementary information accompanies this paper at https://doi.org/10. 1186/s12885-020-6615-Z.

Additional file 1. Supplementary Fig. 1. Representative images of cells with dysmorphic nuclie in monolayers. (a) Immunofluorescence microscopy (IFM) showed deposition of complement on cells with normal nuclei, while a cell with a dysmorphic nucleus in the same field showed decreased complement deposition. (b) Differential interference contrast (DIC) image shows a shrunken cell with a different pattern of complement staining as shown with IFM than cells with normal morphology. (c) Superimposed DIC and IFM images shows that cells with abnormal morphology and nuclei do not deposit complement as cells with normal morphology. Supplementary Fig. 2. EGFR expression and sensitivity to Iressa. (a) qPCR measured normalized EGFR mRNA in 4 HNSCC cell lines, each triangle represents a monolayer. (b) Growth inhibition following $5 \mu \mathrm{M}$ and $10 \mu \mathrm{M}$ Iressa treatment was measured at $24 \mathrm{~h}$ and $48 \mathrm{~h}$, and the average is represented for each cell lines in the bar graph. Uninhibited control growth is set to $100 \%$. Supplementary Fig. 3. Radioactive $\mathrm{C} 1 \mathrm{q}$ binding assay was performed on $\mathrm{HN} 4$ and HN5 cell lines, after $48 \mathrm{~h}$ of EGFR inhibition using $10 \mu \mathrm{mol} / \mathrm{L}$ Iressa. No significant difference in binding between control and Iressa treated cells was found

\section{Abbreviations}

BSA: Bovine serum albumin; CRP: Complement regulatory proteins; EGFR: Epidermal growth factor receptor; ERK: Extracellular signal-regulated kinase; EtD-III: Ethidium homodimer III; FBS: Foetal bovine serum; HIS: Heatinactivated human serum; HNSCC: Head and neck squamous cell carcinoma; HRP: Horse radish peroxidase; NHS: Normal human serum; PVDF: Polyvinylidene difluoride; R-T PCR: Real-time polymerase chain reaction; TCA: Trichloroacetic acid; TCC: Terminal complement complex

\section{Acknowledgements}

The expert technical assistance of Malgorzata Berlikowski and Ingbritt Gustafsson is greatly appreciated.

\section{Authors' contributions}

$\mathrm{AH}$ contributed in experimental design, data acquisition and analysis, writing of the manuscript and making figures, LE provided HNSCC cell lines and generated cetuximab resistant sublines and contributed to drafting and revision. JW provided HNSCC cell lines and contributed to drafting and revision. OS drafted the work and experimental design, contributed in data analysis, writing of the manuscript and revision. The authors read and approved the final manuscript

\section{Funding}

This work was supported by grants from Petrus and Augusta Hedlunds stiftelse, Kgl. Fysiografiska Sällskapet, Greta och Johan Kocks stiftelse, and Crafordska stiftelse. The funding bodies had no role or involvement in the study design, collection and analysis of data, interpretation of results or in writing of the manuscript. Open access funding provided by Lund University.

\section{Availability of data and materials}

All data generated or analysed during this study are included in this published article and its supplementary information files.

Ethics approval and consent to participate

Not applicable.

\section{Consent for publication}

Not applicable.

\section{Competing interests}

The authors declare they have no conflicts of interest regarding this work.

\section{Author details}

'Division of Infection Medicine, Department of Clinical Sciences, Lund University, Lund, Sweden. 'Division of Microbiology, Faculty of Medicine, The University of Jordan, Amman, Jordan. ${ }^{3}$ Division of Oncology, Department of Clinical Sciences, Lund University, Lund, Sweden. ${ }^{4}$ Division of Otorhinolaryngology/H\&N Surgery, Department of Clinical Sciences, Lund University, Lund, Sweden.

Received: 16 October 2019 Accepted: 7 February 2020

Published online: 13 February 2020

\section{References}

1. Mortensen SA, Sander B, Jensen RK, et al. Structure and activation of C1, the complex initiating the classical pathway of the complement cascade. Proc Natl Acad Sci U S A. 2017;114:986-91

2. Garred P, Genster N, Pilely K, et al. A journey through the lectin pathway of complement-MBL and beyond. Immunol Rev. 2016;274:74-97.

3. Cole DS, Morgan BP. Beyond lysis: how complement influences cell fate. Clin Sci (London, England: 1979). 2003;104:455-66.

4. Botto M, Walport MJ. C1q, autoimmunity and apoptosis. Immunobiology. 2002:205:395-406

5. Trendelenburg M, Schifferli JA. Apoptosis and C1q: possible explanations for the pathogenesis of systemic lupus erythematosus. Z Rheumatol. 2000;59: 172-5.

6. Figueroa JE, Densen P. Infectious diseases associated with complement deficiencies. Clin Microbiol Rev. 1991;4:359-95.

7. Ricklin D, Hajishengallis G, Yang K, Lambris JD. Complement: a key system for immune surveillance and homeostasis. Nat Immunol. 2010;11:785-97.

8. Nozaki M, Raisler BJ, Sakurai E, et al. Drusen complement components C3a and C5a promote choroidal neovascularization. Proc Natl Acad Sci U S A. 2006;103:2328-33.

9. Markiewski MM, DeAngelis RA, Strey CW, et al. The Regulation of Liver Cell Survival by Complement. J Immunol (Baltimore, Md. : 1950). 2009;182:5412-8.

10. Carroll MV, Sim RB. Complement in health and disease. Adv Drug Deliv Rev. 2011;63:965-75.

11. Ricklin D, Hajishengallis G, Yang K, Lambris JD. Complement: a key system for immune surveillance and homeostasis. Nat Immunol. 2010;11:785-97. 
12. Thurman JM, Renner B. Dynamic control of the complement system by modulated expression of regulatory proteins. Lab Investig. 2011;91:4-11.

13. Sayama K, Shiraishi S, Miki Y. Distribution of complement regulators (CD46, CD55 and (D59) in skin appendages, and in benign and malignant skin neoplasms. Br J Dermatol. 1992;127:1-4.

14. Uhlén M, Fagerberg L, Hallström BM, et al. Tissue-based map of the human proteome. Science. 2015;347:1260419.

15. Walport MJ. Complement and systemic lupus erythematosus. Arthritis Res. 2002:4:S279-93

16. Tichaczek-Goska D. Deficiencies and excessive human complement system activation in disorders of multifarious etiology. Adv Clin Exp Med : Official Organ Wroclaw Med Univ. 2012;21:105-14.

17. Markiewski MM, Lambris JD. Is complement good or bad for cancer patients? New Perspect Old Dilemma Trends Immunol. 2009;30:286-92.

18. Corrales L, Ajona D, Rafail S, et al. Anaphylatoxin C5a creates a favorable microenvironment for lung cancer progression. J Immunol. 2012;189:4674-83.

19. Coussens LM, Werb Z. Inflammation and cancer. Nature. 2002:420:860-7.

20. Niculescu F, Rus HG, Retegan M, Vlaicu R. Persistent complement activation on tumor cells in breast cancer. Am J Pathol. 1992;140:1039-43.

21. Gallenkamp J, Spanier G, Worle E, et al. A novel multiplex detection array revealed systemic complement activation in oral squamous cell carcinoma. Oncotarget. 2018;9:3001-13.

22. Macor P, Tedesco F. Complement as effector system in cancer immunotherapy. Immunol Lett. 2007;111:6-13.

23. Dechant $M$, Weisner W, Berger S, et al. Complement-dependent tumor cell lysis triggered by combinations of epidermal growth factor receptor antibodies. Cancer Res. 2008;68:4998-5003.

24. Fishelson Z, Donin N, Zell S, Schultz S, Kirschfink M. Obstacles to cancer immunotherapy: expression of membrane complement regulatory proteins (mCRPs) in tumors. Mol Immunol. 2003:40:109-23.

25. Markiewski MM, DeAngelis RA, Benencia F, et al. Modulation of the antitumor immune response by complement. Nat Immunol. 2008:9:1225-35.

26. Elimam H, Papillon J, Takano T, Cybulsky AV. Complement-mediated activation of calcium-independent phospholipase A2y: ROLE OF PROTEIN KINASES AND PHOSPHORYLATION. J Biol Chem. 2013;288:3871-85.

27. Schraufstatter IU, Trieu K, Sikora L, Sriramarao P, DiScipio R. Complement C3a and C5a induce different signal transduction cascades in endothelial cells. J Immunol. 2002;169:2102-10.

28. Cho MS, Vasquez HG, Rupaimoole R, et al. Autocrine effects of tumorderived complement. Cell Rep. 2014;6:1085-95.

29. Baba Y, Fujii M, Tokumaru Y, Kato Y. Present and future of EGFR inhibitors for head and neck squamous cell Cancer. J Oncol. 2012;2012:9.

30. Lichtenberger BM, Gerber PA, Holcmann M, et al. Epidermal EGFR controls cutaneous host defense and prevents inflammation. Sci Transl Med. 2013;5: 199ra111.

31. Coussens LM, Werb Z. Inflammation and cancer. Nature. 2002;420:860-7.

32. Hoesli RC, Moyer JS. Immunotherapy for head and neck squamous cell carcinoma. Curr Oral Health Rep. 2016;3:74-81.

33. Ferris RL. Immunology and immunotherapy of head and neck Cancer. J Clin Oncol : Official J Am Soc Clin Oncol. 2015;33:3293-304

34. Freiser ME, Serafini P, Weed DT. The immune system and head and neck squamous cell carcinoma: from carcinogenesis to new therapeutic opportunities. Immunol Res. 2013;57:52-69.

35. Henriksson E, Kjellén E, Baldetorp B, et al. Comparison of cisplatin sensitivity and the $18 \mathrm{~F}$ fluoro-2-deoxy 2 glucose uptake with proliferation parameters and gene expression in squamous cell carcinoma cell lines of the head and neck. J Exp Clin Cancer Res. 2009;28:1-12.

36. Henriksson E, Baldetorp B, Borg $\AA$, et al. p53 mutation and cyclin D1 amplification correlate with cisplatin sensitivity in xenografted human squamous cell carcinomas from head and neck. Acta Oncol. 2006;45:300-5.

37. Skehan P, Storeng R, Scudiero D, et al. New colorimetric cytotoxicity assay for anticancer-drug screening. JNCI: J Natl Cancer Inst. 1990;82:1107-12.

38. Geback T, Schulz MM, Koumoutsakos P, Detmar M. TScratch: a novel and simple software tool for automated analysis of monolayer wound healing assays. Biotechniques. 2009;46:265-74.

39. Sugita Y, Masuho Y. CD59: its role in complement regulation and potential for therapeutic use. Immunotechnology : Int J Immunol Eng. 1995;1:157-68.

40. Abu-Humaidan AH, Elvén M, Sonesson A, Garred P, Sørensen OE. Persistent Intracellular Staphylococcus aureus in Keratinocytes Lead to Activation of the Complement System with Subsequent Reduction in the Intracellular Bacterial Load. Front Immunol. 2018;9:396-96.
41. Hsu YF, Ajona D, Corrales L, et al. Complement activation mediates cetuximab inhibition of non-small cell lung cancer tumor growth in vivo. Mol Cancer. 2010;9:139.

42. Oshima G, Wennerberg J, Yamatodani T, et al. Autocrine epidermal growth factor receptor ligand production and cetuximab response in head and neck squamous cell carcinoma cell lines. J Cancer Res Clin Oncol. 2012;138: 491-9.

43. McCubrey JA, Steelman LS, Chappell WH, et al. Roles of the Raf/MEK/ERK pathway in cell growth, malignant transformation and drug resistance. Biochimica et Biophysica Acta (BBA) - Mol Cell Res. 2007;1773:1263-84.

44. Kraus S, Seger R, Fishelson Z. Involvement of the ERK mitogen-activated protein kinase in cell resistance to complement-mediated lysis. Clin Exp Immunol. 2001;123:366-74.

45. Ciardiello F, Tortora G. EGFR antagonists in Cancer treatment. N Engl J Med. 2008:358:1160-74

46. Roupe KM, Nybo M, Sjobring U, Alberius P, Schmidtchen A, Sorensen OE. Injury is a major inducer of epidermal innate immune responses during wound healing. J Invest Dermatol. 2010;130:1167-77.

47. Abu-Humaidan AH, Ananthoju N, Mohanty T, et al. The epidermal growth factor receptor is a regulator of epidermal complement component expression and complement activation. J Immunology (Baltimore, Md. : 1950). 2014:192:3355-64.

48. Lichtenberger BM, Gerber PA, Holcmann M, et al. Epidermal EGFR Controls Cutaneous Host Defense and Prevents Inflammation. Sci Transl Med. 2013;5: 199ra111.

49. Ajona D, Pajares MJ, Chiara MD, et al. Complement activation product C4d in oral and oropharyngeal squamous cell carcinoma. Oral Dis. 2015;21:899904.

50. Ravindranath NM, Shuler C. Expression of complement restriction factors (CD46, CD55 \& CD59) in head and neck squamous cell carcinomas. J Oral Pathol Med : Official Publ Int Assoc Oral Pathol Am Acad Oral Pathol. 2006; 35:560-7.

51. Haddad RI, Shin DM. Recent advances in head and neck cancer. N Engl J Med. 2008;359:1143-54.

52. Meyer S, Leusen JH, Boross P. Regul Complement Modulation Act Monoclonal Antibody Ther Cancer mAbs. 2014;6:1133-44.

53. Elvington $\mathrm{M}$, Scheiber $\mathrm{M}$, Yang $\mathrm{X}$, et al. Complement-dependent modulation of antitumor immunity following radiation therapy. Cell Rep. 2014;8:818-30.

54. Janelle $\mathrm{V}$, Langlois M-P, Tarrab E, Lapierre P, Poliquin L, Lamarre A. Transient complement inhibition promotes a tumor-specific immune response through the implication of natural killer cells. Cancer Immunol Res. 2014;2: 200-6.

\section{Publisher's Note}

Springer Nature remains neutral with regard to jurisdictional claims in published maps and institutional affiliations.

\section{Ready to submit your research? Choose BMC and benefit from:}

- fast, convenient online submission

- thorough peer review by experienced researchers in your field

- rapid publication on acceptance

- support for research data, including large and complex data types

- gold Open Access which fosters wider collaboration and increased citations

- maximum visibility for your research: over $100 \mathrm{M}$ website views per year

At $\mathrm{BMC}$, research is always in progress.

Learn more biomedcentral.com/submission 